\title{
Implications of fuel wood scarcity on livelihoods of rural communities of Nyarubuye Sub-County in Kisoro District, south western Uganda
}

\author{
G. Abigaba ${ }^{1}$, G. Niyibizi ${ }^{1}$, Y. Turinayo ${ }^{I}$ and S. Nansereko ${ }^{I}$
}

${ }^{1}$ National Forestry Resources Research Institute, P. O. Box 1752, Kampala, Uganda

Author for correspondence: abigagrace@yahoo.com

\begin{abstract}
Fuelwood scarcity is evident in south western Uganda, where households are using sorghum and maize stalks for cooking as alternatives to the traditional fuelwood. The aim of the study was to assess the implications of fuelwood scarcity on livelihoods of rural communities in Nyarubuye sub-county in Kisoro district in south western Uganda. Systematic random sampling techniques were used to select participating households for the study. Data were collected using direct observation and interviews, using a structured questionnaire that was administered to 80 households in Busengo and Karambi parishes. Face to face interviews were held with key informants, using a checklist. The study showed that the main drivers of fuelwood scarcity in Nyarubuye Sub-county include: land shortage, rapid increase in population, change of land use from communal forested land to crop growing only, lack of integration of trees on farm, inefficient methods of cooking and brick burning. The study also showed that the implications of fuelwood scarcity on livelihoods in the study area were adverse and greatly affected women, as compared to men. They included sickening of eyes, breathing difficulties, snake bites and body dislocations, increased domestic violence (wife beating) and sexual abuse (rape), school attendance inconsistencies for school going children, loss of tree cover and low crop yields. Suggested strategies to reduce fuelwood scarcity in area include: promotion of on farm tree planting activities (agroforestry) and energy saving technologies, availing alternative energy sources such as electricity, enhancing family planning methods, skilling of communities on income generation enterprises especially girls. A byelaw on school children with emphasis on girls to collect firewood during weekends only should be formulated and enforced.
\end{abstract}

Key words: Firewood, maize stover, tree cover

Introduction

Wood fuel is the world's most important form of non-fossil energy burning (FAO,
1999). It provides many people, especially the poor and rural households, with a primary source of energy (Delali et al., 2004). In the 47 Sub-Saharan African 
(SSA) countries, most rural and urban residents rely on wood-based biomass to satisfy their energy needs, especially for cooking (AFREA, 2011). A study by IEA (2006) reported that about $81 \%$ of households in SSA burn solid fuels, far more than any other region in the world, with about $70 \%$ depending on wood-based biomass as their primary cooking fuel while $60 \%$ of urban dwellers also use biomass for cooking.

In Uganda, firewood is the most significant source of energy, and the majority of the people use it to provide energy for domestic use and small-scale industries, for example, brick and tile making, agro processing and fish processing (Forestry Department, 1992; NEMA, 1998; Tabuti et al., 2003). In urban areas, people use charcoal more than firewood. National energy crisis, demand and consumption for firewood in Uganda is estimated to be growing at a rate of 3\% per annum (MEMD, 2012)

However there is fuelwood scarcity in some parts of Uganda, for example in Kisoro district(KDLG, 2009), whereby households use sorghum and maize stalks to cook food for their families. The aim of this study was to assess the socioeconomic impact of fuel wood scarcity on rural peoples' livelihoods in south western Uganda.

\section{Materials and methods}

\section{Study area}

This study was conducted in Nyarubuye Sub-county, located in Kisoro district, which lies in the extreme South Western Uganda, bordered by the Republic of Rwanda to the South, Democratic Republic of Congo to the West, Kanungu district to the North and Kabale district to the East. The total land area of the district is $729.2 \mathrm{Km}^{2}$.

\section{Sampling procedure}

Nyarubuye Sub-county was purposively selected because of its current appalling situation of fuel wood scarcity (KDLG, 2009). Systematic random sampling was used to select the households that participated in the study. The list of the households in each selected parish was generated to form a sampling frame. From Busengo and Karambi parishes, 80 households were randomly selected and household heads interviewed. The study design was based on the assumption that each household is normally distributed and internally homogenous.

\section{Data collection}

Key informants interviews, with local leaders (Sub-county chief, 2 Parish chiefs, 4 Local council Chairmen, District Forestry staff and Women) were carried out using an interview guide. Data were also collected using semi-structured questionnaires administered by the researchers to the 100 respondents. The questionnaire was pretested by random selection of respondents from the study area. The collected data were checked for consistency, coded and entered in Statistical Package for Social Scientists (SPSS version 16.0) computer programme for analysis.

\section{Results}

\section{Socio demographic characteristics}

According to the results, $42.5 \%$ of the respondents were females and $57.5 \%$ were males.

Literacy levels were very low, upto $31.3 \%$ of the respondents had never 
attained any formal education; while $50 \%$ had stopped in primary, and only $22.2 \%$ attained post primary education (Table 1 ).

Most (79.7\%) of the respondents practiced farming as the main source of livelihood; while the rest $(21.3 \%)$ were engaged in other activities such as brick burning besides farming. Majority $(87.5 \%)$ of the respondents earned less than 15 Us dollars per month and only $10 \%$ earned more than 30 Us dollars

\section{Main firewood collectors}

In all age groups, women and girls were more involved in fuelwood collection than their male counterparts ( Fig. 1).

Table 1. Socio-demographic characteristics of the respondents $(\mathrm{N}=80)$ in Kisoro district in south western Uganda

\begin{tabular}{lll}
\hline Variable & $\begin{array}{ll}\text { Fre- } \\
\text { quency }\end{array}$ & $\begin{array}{l}\text { Per- } \\
\text { centage }\end{array}$
\end{tabular}

\begin{tabular}{lll}
\hline Sex & & \\
Male & 44 & 57.5 \\
Female & 36 & 42.5
\end{tabular}

\section{Highest education level}

Primary

Secondary

Tertiary

\section{Main occupation}

Farmer

Civil servant

Business

Brick making

Casual labourer

Pottery

$\begin{array}{rl}25 & 31.3 \\ 40 & 50.0 \\ 12 & 15.2 \\ 3 & 7.0\end{array}$

Monthly income (Ug shs)

$<50,000$
Distance and time taken to collect firewood

The study showed that most $(38.8 \%)$ people walked long distances $(2-3 \mathrm{Km})$ to obtain fuelwood, highest being $5 \%$ who cover a distance of 4-5 Km to fuelwood source and they had to walk the same distance back home (Fig. 2).

Majority (37.5\%) spend 3-4 hours collecting firewood, only $15 \%$ spent more than 6 hours collecting firewood (Fig. 3).

\section{Sources of firewood}

According to the key informants (local leaders, forestry technocrats and women), firewood was mainly collected from the remaining pockets of communal land, woodlot of Eucalyptus belonging to individuals (fallen dry branches would be picked), buying from the owners of woodlots and from scattered fallowland. However, it was disclosed that sorghum and maize stalks were being used for cooking.

\section{Drivers of fuel wood scarcity}

Most (90\%) respondents reported lack of land as the major cause of fuelwood scarcity; followed by cultivation $(73.8 \%)$,this was due to the fact that trees were being for growing crops. Other causes were high human population (60\%), use of energy wasting cooking methods and brick/charcoal burning reported by $51.2 \%$ and $41.2 \%$ of the respondents, respectively (Table 2 ).

\section{Implications of fuelwood scarcity on livelihoods assets}

The implications of fuelwood scarcity on livelihoods in the study area included damaging of sight due to sour smoke 


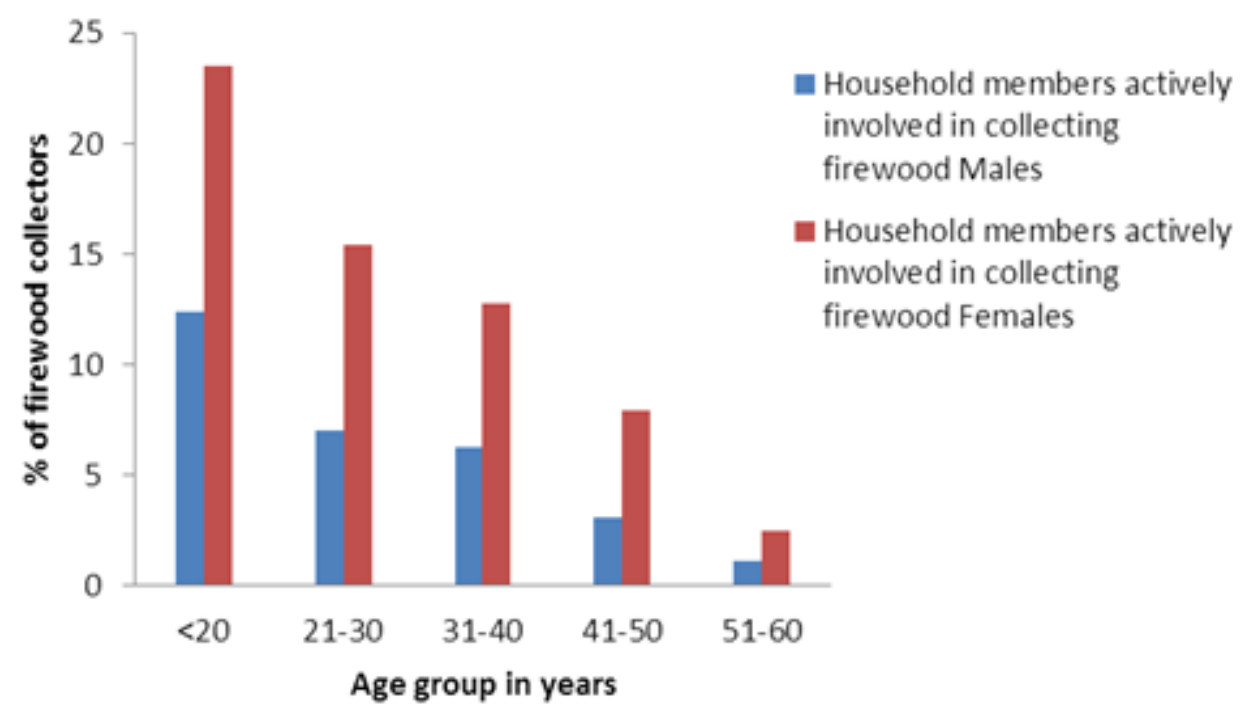

Figure 1. Firewood collectors by age and sex in Kisoro district in south western Uganda.

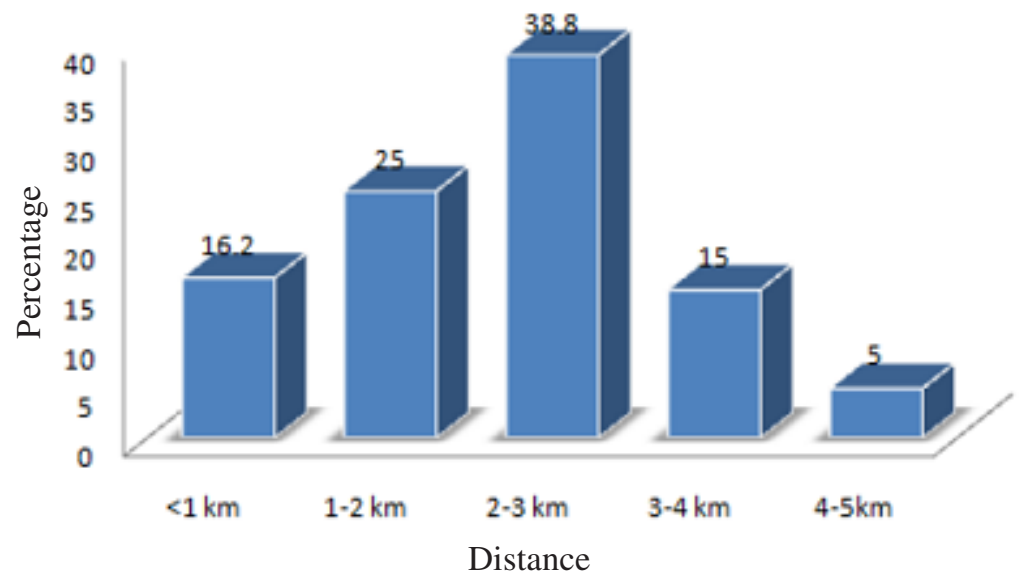

Figure 2. Distance walked to collect firewood among rural communities in Kisoro district in south western Uganda.

entering the eyes; respiratory complications due to sour smoke entering the lungs; physical accidents due to firewood collectors climbing steep and slippery terrain in such of firewood while others falling off from trees; loss of tree cover; low crop yields; inconsistencies in school attendances; domestic violence and rape (Table 3 ).

The study also showed that the implications of fuelwood scarcity on livelihoods in the study area were adverse on human, Natural and Financial capital and greatly affected women as compared to men. 


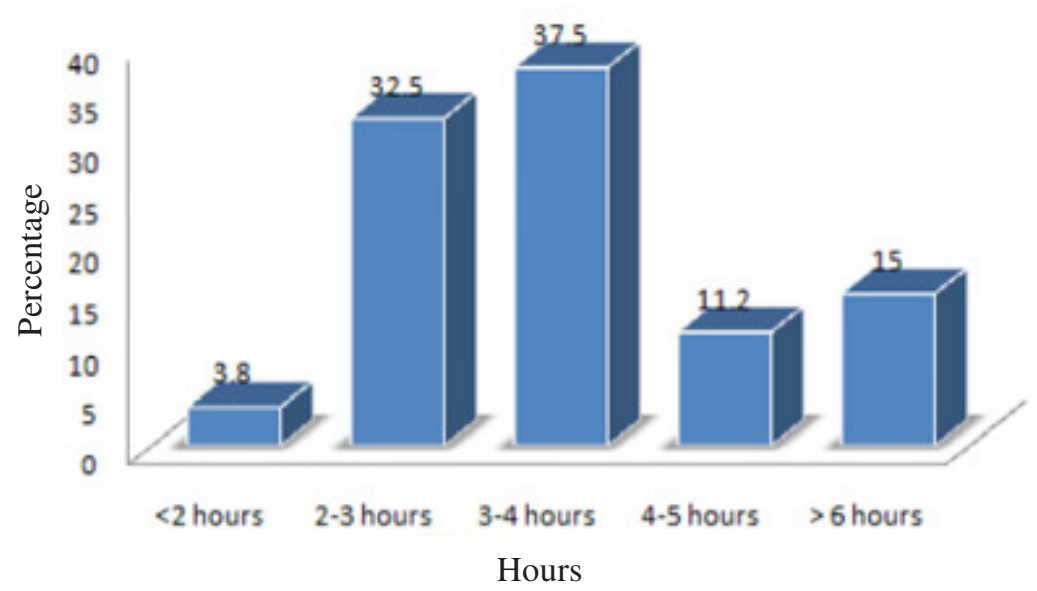

Figure 3. Time taken to collect firewood among rural communities in Kisoro district in south western Uganda.

Table 2. Causes of fuelwood scarcity in Kisoro district in south western Uganda

\begin{tabular}{lcc}
\hline Variable & Frequency & Percentage \\
\hline Land shortage & 72 & 90.0 \\
Converting forested communal land to crop growing only & 59 & 73.8 \\
Population & 48 & 60.0 \\
Use of energy wasting cooking methods & 41 & 51.2 \\
Brick and charcoal burning & 33 & 41.2 \\
\hline
\end{tabular}

Strategies of reducing fuelwood scarcity

Most respondents $(91.2 \%)$ indicated tree planting on farm (Agroforestry) as the best strategy to reduce fuelwood scarcity in Nyarubuye Sub-county. Other strategies are as shown in Table 4.

\section{Discussion}

\section{Main firewood collectors}

In all age groups, women and girls were more involved in fuelwood collection than their male counterparts ( Fig. 2). It involved covering long distances which reduced on their energy to be involved in other activities like farming. The study showed that most fuelwood collectors (38.8\%) walked long distances $(2-3 \mathrm{~km})$ to get to the fuelwood source, highest being $5 \%$ who cover a distance of $4-5 \mathrm{~km}$ to fuelwood source and they have to walk the same distance back home as in Figure 2 This also reduced on their time to be involved in other household activities like preparing food in time, growing of food crops for consumption and for sale and also regular school attendance for children. The International Energy Agency (IEA, 2006) noted that women in rural areas usually spend long hours collecting wood-based biomass, time that would 
Table 3. Implications of fuelwood scarcity on the livelihoods of rural communities in Kisoro district in south western Uganda

\begin{tabular}{lcrrrr}
\hline $\begin{array}{l}\text { Effects of fuel wood scarcity } \\
\text { on livelihoods assets }\end{array}$ & Human & Financial & Natural & Social & \multicolumn{2}{c}{$\begin{array}{c}\text { Sex of } \\
\text { respondents }\end{array}$} \\
\cline { 2 - 5 } & & & & $\begin{array}{r}\text { Male } \\
(\%)\end{array}$ & $\begin{array}{r}\text { Female } \\
(\%)\end{array}$ \\
\hline Eyes problems & & & & 2.1 & 26.1 \\
Breathing difficulties & $*$ & & & 1.9 & 20.4 \\
Snake bites & $*$ & & 3.7 & 8.8 \\
Body dislocation & $*$ & & 4.4 & 15.9 \\
Long time in search of firewood & $*$ & & & 5.7 & 22.5 \\
Lesser meals cooked for the family & $*$ & & & 14.9 & 15.3 \\
Failure to cook hard foods & $*$ & & & 11.3 & 11.6 \\
Loss of tree cover & & & & 25.5 & 25.6 \\
Reduces household income & & $*$ & & 5.7 & 10.6 \\
Increased household income & & $*$ & & 4.0 & 2.5 \\
Children missing school & $*$ & & & 8.8 & 14.6 \\
Low crop yields & $*$ & & 6.6 & 9.9 \\
Domestic violence (Wife beating) & $*$ & & & 0.0 & 9.5 \\
Rape & $*$ & & & 0.0 & 5.4 \\
\hline
\end{tabular}

Table 4. Suggested strategies of increasing fuelwood availability in Kisoro district in south western Uganda

\begin{tabular}{lcc}
\hline Variables & Frequency & Percentage \\
\hline Planting trees on farm (Agroforestry) & 73 & 91.2 \\
Energy saving cooking methods & 27 & 38.8 \\
Biogas/ electricity & 25 & 31.2 \\
Practicing family planning & 18 & 22.5 \\
\hline
\end{tabular}

carry higher value-added to the household if it could be used for child-care, agricultural production, education and other activities.

\section{Sources of firewood}

According to Damte et al. (2012) modern fuels, including electricity, are not common sources of household energy in developing countries, instead, most energy sources (dung, crop residue, and fuelwood) are obtained from own fields, natural forests, and state or government forests. Tree planting for fuelwoood should be stepped up. Government should provide free tree seedlings and technical advice to the farmers.

\section{Drivers of fuel wood scarcity}

Land shortage was reported causing fuelwood scarcity in Nyarubuye subcounty caused by rapid increase in 
population which has led to land fragmentation (Table 2). Majority of the farmers have small scattered fragments of land which they inherited from their parents and planting trees would interfere with other farmers' crops who claimed that trees hinder growth of their crops. This means that if one wants to plant trees, agreement had to be sought with the neighbouring farmers if his trees are to survive. Trees, when not managed compete with crops for water and nutrients which slows crop growth, in some parts of Kenya, people have been pressured into cutting trees because neighbors complained that shade damaged their crops (Brouwer et al., 1997). Change of land use from forested communal land to growing crops only was reported also to cause fuelwood scarcity as it involved cutting down all the trees without replacement in a given area for crop growing. Rapid depletion of tree resources for agriculture expansion in Uganda has led to increasing shortages of firewood (Hamilton 1984). Agroforestry is the intervention which can used to provide fuelwood to the communities and save the natural vegetation.

Poor methods of cooking have also intensified fuelwood scarcity in Nyarubuye Sub-county. The inefficient traditional three stone cook stove which wastes a lot of fuelwood is the one which is mainly used in the study area. Brick and charcoal burning for income generation contributed to fuelwood scarcity in the study area. A bye law should be passed such that all brick and charcoal burners each should plant a woodlot of trees.

\section{Implications of fuelwood scarcity}

Study results showed that the implications of fuelwood scarcity on livelihoods in the study area were adverse on human (Table 2.), natural and financial capital and greatly affected women as compared to men (Table 3). For instance, a higher percentage of female respondents compared to their male counterparts reported health problems, which included: sickening eyes, breathing difficulties due to continuous exposure to massive bitter smoke emissions when cooking using inferior/wet wood like Vernonia amygada;ena; snakebites and body dislocations. Smith (1999) noted that indoor air pollution caused by the burning of inferior fuelwood for cooking and heating results in premature death for an estimated two million women and children each year worldwide.

In the study, both male and female respondents experienced low crop yields (Table 3) because they were using crop remains such as maize and sorghum stalks, as well as bean trashes as fuel for cooking. The use of crop residues is a direct way of denying fertilisers from the soil and since no more fertiliser is added to supplement the soil fertility, land productivity reduces, causing low crop yields). The use of crop residues, which could otherwise be returned to the garden to maintain fertility, as alternative or supplements to fuelwood seriously affect soil fertility by reducing water retention and mineral content. This leads to reduction in agricultural outputs hence directly impinging on food security and income generation for agro-based communities (Gakwaya, 2001). Improved fallows and other soil improvement 
technologies are recommended for soil fertility improvement in the Study area.

\section{Strategies to reduce fuelwood scarcity}

Promotion of agroforestry practices should be emphasized; this will allow farmers with small landholdings to plant trees in their gardens alongside crops. Emphasis should be put on multipurpose tree species, such as Alnus acuminata, clonal Eucalyptus and Grevillea robusta. These species have been tested in Kabale by ICRAF/FORRI and proven to perform well in the South Western Agro-ecological zone.

Communities should be sensitised on the importance of using energy saving cook stoves to reduce firewood wastage; and those willing should be trained on how to make these cook stoves. Also, access to a reliable and affordable electricity and/ or biogas can reduce the number of trees cut for fuelwood. Many trees are cut for fuelwood because there is no alternative source of energy for cooking.

\section{Acknowledgement}

The authors thank National Agricultural Research Organization and National Forestry Resources Research Institute management for financial and moral support.

\section{References}

AFREA, 2011. Wood-Based Biomass Energy Development for Sub-Saharan Africa. African Forest Journal 154: 88-93.

Brouwer, I.D. Hoorweg, J. C. and Van Liere, M.J. 1997. When households run out of fuel: Response of households to decreasing fuelwood availability, Ntcheu District, Malawi. World Development Journal 25(2): 255266.

Delali, B.K.D., Witkowski, E.T.F. and Shackleton, M.C. 2004. The fuelwood crisis in EC-FAO.1998-2002. Forest resources and plantations of the Gambia, Data Collection and Analysis for Sustainable Forest Management in ACP Countries, Paris.

FAO. 1999. The State of the World's Forests, Food and Agriculture Organization, Rome, Italy.

Forestry Department,1992. The national biomass study, Phase I. Technical report. Forest Department, Nakawa, Uganda. 229pp.

Hamilton, A.C. 1984. Deforestation in Uganda. Oxford University Press, Nairobi, Kenya.

IEA. 2006. World Energy Outlook. Chapter 15, Energy for Cooking in the Developing World. IEA/OECD Paris , France.

Kisoro District Local Government (KDLG), 2009. State of Environment Report 2007/2008, Kisoro district. FAO. 1999. The State of the World's Forests, Food and Agriculture Organization, Rome, Italy.

NEMA., 1998. State of the environmental report for Uganda. National Environmental Management Authority, Government of Uganda.

Smith, K.R. 1999. Fuel combustion, air pollution exposure, and health: The situation in developing countries. Annual Review Energy Environment 1993 18:529-566.

Southern Africa: Relating fuelwood use to livelihoods in a rural village. Geo Journal 60:123-133. 